\title{
Introducción a las políticas actuales en México de la situación de los animales no humanos ante pandemias
}

\section{Elizabeth Montero Romero}

MA Derecho Animal y Sociedad (UAB)

Abogada y editora (México)

Cita recomendada. MONTERO ROMERO, E., Introducción a las políticas actuales en México de la situación de los animales no humanos ante pandemias, dA. Derecho Animal (Forum of Animal Law Studies) 11/4 (2020). - DOI https://doi.org/10.5565/rev/da.531

Resumen

El presente trabajo señala las políticas que se tienen actualmente en México respecto a los animales de compañía, los animales en zoológicos, en los acuarios, en la producción, y en la experimentación o investigación, ante cualquier epidemia o pandemia, como en el caso que estamos experimentando: COVID19, enfermedad causada por el coronavirus SARS-CoV-2.

Palabras clave: COVID19; protocolo animales de compañía; animales en zoológicos; animales en acuarios; animales de producción; autoridades; pandemia; relación humano-animal; México; consecuencias; prevención; leyes mexicanas.

Abstract - Introduction to the current policies in Mexico for non-human animals in the face of pandemics

This work outlines the policies currently in place in Mexico with respect to companion animals, animals in zoos, in aquariums, in production, and in experimentation or research, in the face of any epidemic or pandemic, as in the case we are experiencing: COVID19, a disease caused by the SARS-CoV-2 coronavirus.

Keywords: COVID19; care guidelines for companion animals; care guidelines for zoo animals; care guidelines for aquarium animals; care guidelines for farm animals; authorities; pandemic; human-animal relationship; Mexico; consequences; prevention; Mexican law. 
Para iniciar el presente escrito, es importante destacar que en México y a nivel internacional la relación entre la salud animal y la salud humana siempre ha existido, por eso todos los humanos deben fomentar y fortalecer sus sistemas de vigilancia epidemiológica con la finalidad de que haya una buena sanidad animal. En nuestro país la atención de las zoonosis se documenta desde mediados de los años setenta en diferentes programas nacionales de salud ${ }^{1}$.

Recordemos que las zoonosis son enfermedades que sufren los animales, cuyos agentes patógenos responsables de estas enfermedades pueden ser transmitidas en forma directa o indirecta a los humanos. Esa sería la definición más simple de lo que es una zoonosis o una enfermedad zoonótica ${ }^{2}$. Las enfermedades zoonóticas representan un problema de salud pública debido a que afectan a una gran parte de la población tanto en zonas urbanas como rurales. Una enfermedad exótica puede presentarse en México a través de 4 factores: el comercio, el turismo, la movilización de animales de manea legal o ilegal, o incluso por el cambio climático $^{3}$.

Cabe recordar que un animal enfermo puede infectar a todas las personas en México, así como el cambio climático ${ }^{4}$ puede retornar enfermedades que se tenían erradicadas, por ello la importancia de contar con buenas políticas de sanidad animal. De ahí la mayor parte de las veces es necesario tomar acciones como el sacrificio animal o la restricción de entrada y salida de animales del país.

Como paréntesis y antes de continuar con el presente trabajo, se debe destacar la actual definición de bienestar animal en nuestra Ley Federal de Sanidad Animal:

Conjunto de actividades encaminadas a proporcionar comodidad, tranquilidad, protección y seguridad a los animales durante su crianza, mantenimiento, explotación, transporte y sacrificio ${ }^{5}$.

Bien, en México no es la primera crisis de salud de esta índole como el COVID-19 que se ha experimentado, la última que se vivió en nuestro país fue en abril en el año 2009 cuando fuimos el epicentro del virus AH1N1. He aquí que se fortalecieron y estipularon protocolos de acción ante nuevas pandemias ${ }^{6}{ }^{7}$

Tal como se encuentra actualmente nuestro país, que seguimos teniendo cada día más casos de contagio, pero ahora de COVID-19, y aunque este virus se transmite de humano a humano nunca hay que eludir la salud de los animales ${ }^{8}$.

Es relevante no dejar de tomar en cuenta la salud de animales no humanos debido a varios factores, entre ellos contar con suministros alimentarios más seguros, mayor productividad agrícola, impactos

\footnotetext{
${ }^{1}$ BLOG DE PRODUCTORA NACIONAL DE BIOLÓGICOS VETERINARIOS Página web:

https://www.gob.mx/pronabive/es/articulos/las-enfermedades-zoonoticas-en-mexico?idiom=es [Última consulta: 26 de noviembre de 2020]

${ }^{2}$ Palabras del Dr. Celso Ramos García, investigador en Ciencias Médicas del Centro de Investigación sobre Enfermedades Infecciosas (CISEI) del Instituto Nacional de Salud Pública (INSP). Página web:

https://www.insp.mx/avisos/4732-enfermedades-zoonoticas-18.html [Última consulta: 25 de noviembre de 2020]

${ }^{3}$ Industria Farmacéutica Veterinaria de México. Página Web: https://infarvet.org.mx/salud-animal-300320/ [Última consulta: 08 de septiembre de 2020]

${ }^{4}$ Los cambios climáticos y de hábitat hacen que las enfermedades emergentes y reemergentes se conviertan en un problema global, dado que las poblaciones urbanas están en continuo crecimiento, aumentando las oportunidades para la transmisión de estas enfermedades tanto de persona a persona como de animales a personas, en el caso de las enfermedades zoonóticas. Muchas veces los servicios de salud pública no están equipados para lidiar con ciertos brotes infecciosos, por lo que la Organización Mundial de la Salud (OMS) ha calculado que el calentamiento global puede estar causando la muerte de hasta 150.000 personas al año.

VERDERA, J. Medwave 2008 Oct;8(9):e1716 doi: 10.5867/medwave.2008.09.1716

Página web: https://www.medwave.cl/link.cgi/Medwave/Revisiones/RevisionTemas/1716?ver=sindiseno

También se puede consultar más en la página web de la FAO: http://www.fao.org/3/i2498s/i2498s.pdf [Últimas consultas: 26 de noviembre de 2020]

${ }^{5}$ Bienestar Animal. Ley Federal de Sanidad Animal. Publicada en el Diario Oficial de la Federación el 25 de julio de 2007. Última reforma el día 16 de febrero de 2018. Página web: http://www.diputados.gob.mx/LeyesBiblio/pdf/LFSA_160218.pdf [Última consulta: 08 de septiembre de 2020]

${ }^{6}$ DECRETO por el que se ordenan diversas acciones en materia de salubridad general, para prevenir, controlar y combatir la existencia y transmisión del virus de influenza estacional epidémica. Publicada en el Diario Ofícial de la Federación el 25 de abril de 2020. Página Web: http://dof.gob.mx/nota_detalle.php?codigo=5088366\&fecha=25\%2F04\%2F2009 =[Última consulta: 24 de noviembre de 2020]. SANTILLANA, G. Virus SARS-CoV-2, Enfermedad COVID-19 La emergencia de salud pública ante la legislación mexicana (Ciudad de México, 2020) 30

${ }^{7}$ Para consultar más de este protocolo ver:

http://www.cenaprece.salud.gob.mx/programas/interior/emergencias/descargas/pdf/Plan_Nacional_Influenza.pdf [Última consulta: 26 de noviembre de 2020]

${ }^{8}$ SUÁREZ, V et al. Epidemiology of COVID-19 in Mexico: from the 27th of February to the 30th of April 2020. Epidemiología de COVID-19 en México: del 27 de febrero al 30 de abril de 2020. Revista clínica española vol. 220,8 (2020). 463-471. DOI:10.1016/j.rce.2020.05.007

9 Mayo Clinic. https://www.mayoclinic.org/es-es/diseases-conditions/coronavirus/expert-answers/can-pets-get-coronavirus/faq20486391=[Última consulta: 24 de noviembre de 2020]
}

200 Derecho Animal. Forum of Animal Law Studies, vol. 11/4 
ambientales reducidos, el uso reducido de antibióticos y el bienestar animal es mejor ${ }^{10}$. A pesar de que la mayoría de los factores antes citados parten de una postura antropocéntrica ${ }^{11}$, podemos "rescatar" el último factor que parte desde la postura proteccionista hacia los animales per se.

Volviendo al tema que nos ocupa, el de las políticas establecidas para los animales no humanos en México ante una Zoonosis o Pandemia, debemos abordar la legislación mexicana. Empecemos con la Constitución Política de los Estados Unidos Mexicanos, para el caso de una emergencia sanitaria debemos recurrir al artículo 4 párrafo 4 to. el cual dice:

Toda persona tiene derecho a la protección de la salud. La Ley definirá las bases y modalidades para el acceso a los servicios de salud y establecerá la concurrencia de la Federación y las entidades federativas en materia de salubridad general, conforme a lo que dispone la fracción XVI del artículo 73 de esta Constitución ${ }^{12}$.

Lo anterior quiere decir que el gobierno mexicano está obligado a proporcionar el más alto nivel de salud posible. Así mismo la Segunda Sala de la Suprema Corte de Justicia de la Nación ha interpretado este artículo diciendo que:

El contenido del derecho a la salud establecido en la Constitución Política de los Estados Unidos Mexicanos por una parte el estado tiene la obligación inmediata de asegurar a las personas al menos, un nivel esencial del derecho a la salud y, por otra, una de cumplimiento progresivo, consistente en lograr su pleno ejercicio por todos los medios apropiados, hasta el máximo de los recursos de que disponga. De ahí que se configurará una violación directa a las obligaciones del Pacto cuando, entre otras cuestiones, el Estado Mexicano no adopte medidas apropiadas de carácter legislativo, administrativo, presupuestario, judicial o de otra índole, para dar plena efectividad al derecho indicado. ${ }^{13}$

Avanzando en nuestro texto constitucional, se observa que el artículo 29 dispone que en los casos de invasión, perturbación grave de la paz pública, o de cualquier otro que ponga a la sociedad en grave peligro o conflicto, solamente el Presidente de los Estados Unidos Mexicanos, con la aprobación del Congreso de la Unión o de la Comisión Permanente cuando aquel no estuviere reunido, podrá restringir o suspender en todo el país o en lugar determinado el ejercicio de los derechos y las garantías que fuesen obstáculo para hacer frente, rápida y fácilmente a la situación; pero deberá hacerlo por un tiempo limitado, por medio de prevenciones generales. ${ }^{14}$

En cuanto a los animales no humanos sólo se alude en el artículo 4 (mediante interpretación) que "toda persona tiene derecho a un medio ambiente sano para su desarrollo y bienestar. El Estado garantizará el respeto a este derecho. El daño y deterioro ambiental generará responsabilidad para quien lo provoque en términos de lo dispuesto por la ley". ${ }^{15}$

Escrutando ahora la Ley Orgánica de la Administración Pública Federal, podemos constatar que en el artículo 35 fracción IV se desprende que quien tiene la competencia en cuanto a sanidad animal es la Secretaría de Agricultura y Desarrollo Social ${ }^{16}$, en adelante SADER.

\footnotetext{
${ }^{10}$ USDA National Institute of Food and Agriculture. Importance of animal health. Página Web: https://nifa.usda.gov/topic/animalhealth [Última consulta: 26 de noviembre de 2020]

${ }^{11}$ Entiéndase el término antropocentrismo de acuerdo a la Real Academia Española (RAE): "Filos. Doctrina o teoría que supone que el hombre es el centro de todas las cosas, el fin absoluto de la naturaleza y punto de referencia de todas las cosas: el antropocentrismo se opone al teocentrismo." Y conforme lo expresado por Gerardo Anaya Duarte, se habla de la predominancia valoral del ser humano con respecto a todo lo demás existente y se establecen, por lo tanto, subordinaciones. ANAYA,G. Antropocentrismo ¿Un concepto equívoco? (México, 2014) 2

${ }_{12}$ Artículo 4, párrafo $4^{\circ}$ de la Constitución Política de los Estados Unidos Mexicanos. Publicado en el Diario Oficial de la Federación el 05 de febrero de 1917. Última reforma el día 08 de mayo de 2020. Página Web:

http://www.diputados.gob.mx/LeyesBiblio/pdf/1_080520.pdf [Última consulta: 08 de septiembre de 2020]

13 Tesis: 2a. CVIII/2014 (10a.) emitida por la Segunda Sala de la Suprema Corte de Justicia de la Nación en la Décima Época, publicada en la Gaceta del Semanario Judicial de la Federación, Libro 12, noviembre de 2014, Tomo I, Pág. 1192. SALUD. DERECHO AL NIVEL MÁS ALTO POSIBLE. ÉSTE PUEDE COMPRENDER OBLIGACIONES INMEDIATAS, COMO DE CUMPLIMIENTO PROGRESIVO.

${ }^{14}$ Artículo 29 de la Constitución Política de los Estados Unidos Mexicanos. Publicado en el Diario Oficial de la Federación el 05 de febrero de 1917. Última reforma el día 08 de mayo de 2020. Página Web:

http://www.diputados.gob.mx/LeyesBiblio/pdf/1_080520.pdf [Última consulta: 08 de septiembre de 2020]

15 Artículo 4 párrafo $5^{\circ}$. de la Constitución Política de los Estados Unidos Mexicanos. Publicado en el Diario Oficial de la Federación el 05 de febrero de 1917. Última reforma el día 08 de mayo de 2020. Página Web:

http://www.diputados.gob.mx/LeyesBiblio/pdf/1_080520.pdf [Última consulta: 08 de septiembre de 2020]

16 Artículo 35 de la Ley Orgánica de la Administración Pública Federal. Publicado en el Diario Oficial de la Federación el 29 de
} 
La regulación de la sanidad animal se puede encontrar en la Ley Federal de Sanidad Animal, y su reglamento. En la Ley Federal de Sanidad Animal se pueden encontrar las medidas zoosanitarias actuales del país. Las medidas zoosanitarias tienen por objeto proteger la vida, salud y bienestar de los animales incluyendo su impacto sobre la salud humana, así como asegurar el nivel adecuado de protección zoosanitaria en todo el territorio nacional ${ }^{17}$.

Para complementar cualquier consulta en cuanto sanidad animal, cabe señalar que la SADER ha expedido entre otra normatividad dos elementos claves para este tema. La primera normatividad es la Norma Oficial Mexicana NOM-046-ZOO-1995, Sistema Nacional de Vigilancia Epizootiológica ${ }^{18}$ y la Norma Oficial Mexicana NOM-033-SAG/ZOO-2014, Métodos para dar Muerte a los Animales Domésticos y Silvestres ${ }^{19}$.

En las referencias abajo señaladas al pie de la página puede consultar dichas normas oficiales con la finalidad de extender más la información, pues no es objeto del presente trabajo extender o reproducir dicha información.

Adicional a estas normas oficiales mexicanas, en adelante NOMS, es recomendable consultar la Norma Mexicana ${ }^{20} N M X A A-165-S C F I-2014$ la cual establece los Requisitos para la Certificación con respecto al Bienestar Animal, Conservación, Investigación, Educación y Seguridad en los Zoológicos. ${ }^{21}$

De la norma oficial mexicana NOM-033-SAG/ZOO-2014 podemos señalar que la forma de matanza "humanitaria" que señala es la matanza de control o la matanza zoosanitaria ${ }^{22}$, que en caso de emergencia sanitaria causada por enfermedades provenientes de animales debe adoptarse como medida. También en México contamos con un Manual de procedimientos para el sacrificio humanitario y la disposición sanitaria en emergencias zoosanitarias. Así como un Manual de procedimientos de rastreo epidemiológico y atención de casos sospechosos en emergencias zoosanitarias ${ }^{23}$.

Es importante apuntar que en situaciones de riesgo epidemiológico la Secretaría de Salud ${ }^{24}$, en adelante la SSA, también juega un papel importante, pues esta es quien determina cuando debe realizarse una matanza porque considere a ciertos animales como riesgo de salud y físico para la población humana o cuando sea necesario evitar que se establezca o propague una enfermedad que afecte al humano ${ }^{25}$.

Por lo tanto, se considerará un peligro para la salud en México la tenencia, uso o aprovechamiento de animales de cualquier tipo, cuando sean:

Fuente de infección, en el caso zoonosis;

Huésped intermediario de vehículos que puedan contribuir a la diseminación de enfermedades transmisibles al hombre y; Vehículo de enfermedades transmisibles al hombre, a través de sus

diciembre de 1976. Última reforma el día 22 de enero de 2020. Página Web:

http://www.diputados.gob.mx/LeyesBiblio/pdf/153_220120.pdf [Última consulta: 08 de septiembre de 2020]

${ }_{17}$ Artículo 14 de la Ley Federal de Sanidad Animal. Publicado en el Diario Oficial de la Federación el 25 de julio de 2007. Última reforma el día 16 de febrero de 2018. Página Web: http://www.diputados.gob.mx/LeyesBiblio/pdf/LFSA_160218.pdf [Última consulta: 25 de noviembre de 2020]

${ }^{18}$ NOM-046-ZOO-1995, SISTEMA NACIONAL DE VIGILANCIA EPIZOOTIOLÓGICA. Publicado en el Diario Oficial de la Federación el día 19 de febrero de 1997. Última reforma el 29 de enero de 2001. Página web:

http://publico.senasica.gob.mx/includes/asp/download.asp?IdDocumento=530\&IdUrl=1014\&objeto=Documento\&IdObjetoBase=53 $0 \&$ down=true [Última consulta: 08 de septiembre de 2020]

${ }^{19}$ NOM-033-SAG/ZOO-2014, Métodos para dar Muerte a los Animales Domésticos y Silvestres. Publicado en el Diario Oficial de la Federación el día 26 de agosto de 2015. Página web:

https://normateca.agricultura.gob.mx/sites/default/files/normateca/Documentos/NORMA\%20Oficial\%20Mexicana\%20NOM\%2003 3SAG\%20ZOO\%202014\%2C\%20M\%C3\%A9todos\%20para\%20dar\%20muerte $\% 20 \mathrm{a} \% 201$ os\%20animales $\% 20$ dom $\%$ C3\%A9sticos $\% 20 y \% 20$ silvestres.pdf [Última consulta: 08 de septiembre de 2020]

${ }^{20}$ Cabe señalar la diferencia entre una norma oficial mexicana y una norma mexicana:

Las NOM tienen como principal objetivo prevenir los riesgos de la salud, la vida y el patrimonio y por lo tanto son de observancia obligatoria. Estas regulaciones técnicas presentan la información, los requisitos, las especificaciones, los procedimientos y la metodología que hacen que las dependencias gubernamentales puedan establecer parámetros medibles, de forma que se eviten riesgos a la población, al medio ambiente y

a los animales. A diferencia de las NOM, las NMX (Normas Mexicanas) se definen como normas voluntarias, no obligatorias. Sin embargo, si una NOM hace referencia a una NMX, esta NMX adquirirá el carácter de obligatoria.

http://www.protlcuem.gob.mx/swb/work/models/siam/posicionamiento/articulos_posicionamiento/Clasificaci $\% \mathrm{C} 3 \% \mathrm{~B} 3 \mathrm{n} \% 20 \mathrm{de} \% 20$ $10 \mathrm{o} \% 20 \mathrm{diferentes} \% 20$ tipos$\% 20 \mathrm{de} \% 20$ normas\%20oficiales\%20mexicanas.pdf [Última consulta: 25 de noviembre de 2020]

${ }^{21}$ Norma Mexicana AA 165 SCFI 2014. Publicado en el Diario Oficial de la Federación el día 22 de septiembre de 2014. Página Web: http://www.economia-nmx.gob.mx/normas/nmx/2010/nmx-aa-165-scfi-2014.pdf [Última consulta: 08 de septiembre de 2020]

22 Punto 3.26 de la NOM-033-SAG/ZOO-2014. Matanza zoosanitaria: Medida extrema que realiza, ordena o supervisa la Secretaría en uno o varios animales, con el fin de evitar que se establezca o propague una enfermedad que afecte a los animales o al humano.

23 Ambas se encuentran en las siguientes páginas web: https://www.gob.mx/senasica/documentos/manuales-cpa?state=published [Última vez citadas el 9 de septiembre de 2020]

${ }^{24}$ RODRÍGUEZ, M. La Constitución en esquemas. (Ciudad de México, 2015) 233

${ }^{25}$ VON AGUILAR, G. Derecho y pandemias. (Ciudad de México, 2019) 94

202 Derecho Animal. Forum of Animal Law Studies, vol. 11/4 


$$
\operatorname{productos}^{26} \text {. }
$$

Se puede entonces apreciar que, por un lado, la SSA en casos de emergencias epidemiológicas determinará la medida a aplicar y por el otro lado la SADER es quien ejecutará la acción, pues la sanidad animal es el campo de competencia de la segunda secretaría citada (SADER), mientras que la Secretaría de Salud es la especialista general en cuanto a salud y, por tanto, en riesgos sanitarios ${ }^{27}$.

Ahora bien, volviendo al artículo 35 de la LOAPF podemos enfatizar que la SSA también tiene injerencia en cuanto al comercio exterior, transporte, importación y exportación de los animales que se encuentren en territorio mexicano. Esta idea o artículo la podemos correlacionar con el artículo 157 de la Ley General de Salud donde se establece la prohibición de introducir o transportar por territorio nacional animales o cadáveres de estos, que padezcan una enfermedad transmisible al hombre ${ }^{28}$.

Cabe destacar que las Secretarías de Seguridad Pública, Secretarías de la Defensa Nacional, Secretaría de Marina, la Secretaría de Medio Ambiente y Recursos Naturales, así como las autoridades estatales y municipales, colaborarán con la SADER en el ejercicio de sus atribuciones, cuando por la naturaleza y gravedad del problema así lo determine esta última ${ }^{29}$.

La SADER mediante el Servicio Nacional de Sanidad Inocuidad y Calidad Agroalimentaria (en adelante la SENASICA) es la encargada de establecer las políticas nacionales, programas y acciones en materia de epidemiología veterinaria en coordinación con los diferentes actores que conforman los servicios veterinarios oficiales, el sector público y privado. También SENASICA se encarga de evitar afectaciones en la salud pública.

Dentro de SENASICA hay dos equipos de trabajo relevantes como lo son el Consejo Técnico Consultivo Nacional de Sanidad Animal (CONASA) y el Comité Consultivo Nacional de Normalización de Protección Zoosanitaria (CONAPROZ).

Lo anterior se fortalece con la coordinación y operación del Sistema Nacional de Vigilancia Epidemiológica (SIVE), el Dispositivo Nacional de Emergencia de Salud Animal (DINESA) y la infraestructura de primer nivel a través de sus 2 laboratorios: Centro Nacional de Servicios de Diagnóstico en Salud Animal (CENASA) y del Centro Nacional de Servicios de Constatación en Salud Animal (CENAPA). ${ }^{30}$

En casos de brotes de enfermedades que pongan en riesgo la salud de la población, la Dirección General de Salud Animal activa y coordina en forma inmediata al DINESA de acuerdo a los planes de emergencia, y como apoyo están los grupos Estatales de Emergencia de Sanidad Animal (GEESA). Y los conforman personal técnico oficial y privado previamente capacitado para dar respuesta a una emergencia sanitaria. ${ }^{31}$

Ahora bien, para nuestro país las enfermedades y plagas exóticas y endémicas de notificación inmediata obligatoria que no se encuentran en el territorio nacional, o que han sido erradicadas del país, y que por su rápida diseminación pueden afectar a la población animal terrestre y acuícola y en algunos casos ser un riesgo para la salud pública son entre otras (de un listado de 97 enfermedades):

\section{- ENFERMEDAD DE AUJESZKY [Herpesvirus1 (HVP-1)] \\ - FIEBRE AFTOSA (Aphthovirus) \\ - VIRUELA (Orthopoxvirus, Capripoxvirus) \\ - PESTE EQUINA AFRICANA (Orbivirus) \\ - FIEBRE PORCINA CLASICA (Pestivirus) ${ }^{32}$}

\footnotetext{
${ }^{26}$ Artículo 156 de la Ley General de Salud. Publicada en el Diario Oficial de la Federación el 7 de febrero de 1984. Última reforma publicada el 24 de enero de 2020. Página Web: http://www.diputados.gob.mx/LeyesBiblio/pdf/142_240120.pdf [Última consulta: 08 de septiembre de 2020]

27 Artículo 140 de la Ley General de Salud. Publicada en el Diario Oficial de la Federación el 7 de febrero de 1984. Última reforma publicada el 24 de enero de 2020. Página Web: http://www.diputados.gob.mx/LeyesBiblio/pdf/142_240120.pdf [Última consulta: 08 de septiembre de 2020]

${ }^{28}$ Artículo 157 de la Ley General de Salud. Publicada en el Diario Oficial de la Federación el 7 de febrero de 1984. Última reforma publicada el 24 de enero de 2020. Página Web: http://www.diputados.gob.mx/LeyesBiblio/pdf/142_240120.pdf [Última consulta: 08 de septiembre de 2020]

${ }^{29}$ VON AGUILAR, G. Derecho y pandemias. (Ciudad de México, 2019) 96

${ }^{30}$ SENASICA. Salud Animal. Acciones para mejorar el estatus zoosanitario del país. Página Web:

https://www.gob.mx/senasica/acciones-y-programas/acciones-estrategicas-de-salud-animal.pdf [Última consulta: 08 de septiembre de 2020]

${ }^{31}$ SENASICA. Dispositivo Nacional de Emergencia de Sanidad Animal (DINESA). Establece medidas de prevención, control y erradicación. Página web: https://www.gob.mx/senasica/acciones-y-programas/dispositivo-nacional-de-emergencia-de-sanidadanimal-dinesa [Última consulta: 08 de septiembre de 2020]

${ }^{32}$ En esta página web se puede consultar las 97 enfermedades que son de notificación obligatoria. Artículo 6 del Acuerdo mediante el cual se dan a conocer en los Estados Unidos Mexicanos las enfermedades y plagas exóticas y endémicas de notificación obligatoria de los animales terrestres y acuáticos. Publicado en el Diario Oficial de la Federación el 29 de noviembre de 2018.Página Web:
} 
Concluyendo este apartado uno se podrá dar cuenta que realmente existen tantas enfermedades de las cuales hay que estar vigilantes (y no solamente de una sola enfermedad como el COVID19). Así mismo podemos sintetizar que la SSA es quien en casos de emergencias epidemiológicas determinará la medida a aplicar y por el otro lado la SADER (mediante la SENASICA) es quien ejecutará dicha acción, y en caso de necesitar ayuda adicional dichas instituciones se pueden apoyar de las Secretarías de Seguridad Pública, Secretarías de la Defensa Nacional, Secretaría de Marina, la Secretaría de Medio Ambiente y Recursos Naturales, así como de las autoridades estatales y municipales. Todo esto cumpliendo con lo establecido en la normatividad antes citada.

\section{Políticas establecidas para las diferentes categorizaciones de animales.}

A continuación, este trabajo de investigación se ocupará en señalar de forma general y no específica cómo ha sido el actuar en todos estos meses en cuanto a los animales de compañía, en cuanto a los animales silvestres, animales en zoológicos y acuarios, animales en la producción, y animales en la experimentación o investigación científica.

En el caso de los animales de compañía la SENASICA ha exhortado a todos los médicos veterinarios y poseedores de mascotas del país a aplicar medidas preventivas con el objetivo de prevenir y detectar posibles casos en animales expuestos a personas contagiadas ${ }^{33}$.

En el caso de los Médicos Veterinarios Zootecnistas, la Secretaría de Salud pidió que en sus consultorios u hospitales veterinarios reforzar las medidas básicas de bioseguridad como: el lavado de manos antes y después de estar con animales o tocar sus pertenencias ${ }^{34}$.

Se reitera indispensable el uso de tapetes sanitarios y equipo de protección como cubrebocas, guantes y batas desechables y llevar a cabo acciones de limpieza y desinfección constante de todos los pisos y mobiliario del consultorio u hospital veterinario ${ }^{35}$.

Otra medida señala que los veterinarios deben considerar en la historia clínica de la mascota los antecedentes de COVID-19 en los propietarios y orientarlos para que las personas que han contraído esta enfermedad limiten su acercamiento con los animales, esto incluye abrazarla, acariciarla, besarla, dejarse lamer y compartir la comida. Usar mascarilla y guantes en todo momento para protegerlos ${ }^{36}$.

Si durante la visita en el consultorio del MVZ existe la sospecha fundada de que un animal puede estar infectado de COVID-19, el veterinario debe conservar en refrigeración una muestra de hisopado nasal o faríngeo en un tubo estéril para que personal oficial lo traslade al laboratorio de alta seguridad del SENASICA. Los médicos veterinarios deben notificar al SENASICA mediante una línea telefónica. ${ }^{37}$

Si el resultado de la prueba de detección del virus que causa el COVID-19 de su mascota es positivo, se deberá aislar a su mascota de todas las demás personas, incluidas otras mascotas. Esto es que la mascota se quede en una "sala de enfermo" y siga las recomendaciones del MVZ para su tratamiento. Es posible que algunas mascotas necesiten pruebas de seguimiento para saber si siguen dando positivo para el virus que causa el COVID- $19^{38}$.

La razón por la que se citan estos datos en cuanto a los animales de compañía o mascotas es por un lado mencionar cuál ha sido el protocolo a seguir de la SENASICA en cuanto a los animales de compañía, y por el otro lado, recalcar a la sociedad mexicana que con una correcta aplicación de dichos cuidados, el riesgo de que las mascotas transmitan el COVID-19 a las personas se considera bajo, por lo que no existe motivo alguno en ningún momento para abandonar o renunciar a mascotas ${ }^{39}$.

\footnotetext{
http://www.dof.gob.mx/nota_detalle.php?codigo=5545304\&fecha=29/11/2018 [Última consulta: 08 de septiembre de 2020]

${ }^{33}$ SENASICA. Recomendaciones para prevenir COVID-19 en animales. Página Web:

https:/www.gob.mx/senasica/articulos/recomendaciones-para-prevenir-covid-19-en-animales?idiom=es [Última consulta: 08 de septiembre de 2020]

${ }^{34}$ SENASICA. Recomendaciones para prevenir COVID-19 en animales. Página Web:

https:/www.gob.mx/senasica/articulos/recomendaciones-para-prevenir-covid-19-en-animales?idiom=es [Última consulta: 08 de septiembre de 2020]

${ }^{35}$ CENTROS PARA EL CONTROL Y LA PREVENCION DE ENFERMEDADES Página Web:

https://espanol.cdc.gov/coronavirus/2019-ncov/community/veterinarians.html [Última consulta: 25 de noviembre de 2020]

36 Idem

37 SENASICA. Emite Agricultura recomendaciones para prevenir y detectar contagio de la COVID-19 en animales

Página Web: https:/www.gob.mx/senasica/prensa/emite-agricultura-recomendaciones-para-prevenir-y-detectar-contagio-de-lacovid-19-en-animales-240184?idiom=es

${ }^{38}$ SENASICA. Emite Agricultura recomendaciones para prevenir y detectar contagio de la COVID-19 en animales. Página Web: https://www.gob.mx/senasica/prensa/emite-agricultura-recomendaciones-para-prevenir-y-detectar-contagio-de-la-covid-19-enanimales-240184 [Última consulta: 08 de septiembre de 2020]

${ }^{39}$ CENTROS PARA EL CONTROL Y LA PREVENCION DE ENFERMEDADES Página Web:

204 Derecho Animal. Forum of Animal Law Studies, vol. 11/4
} 
En cuanto al rubro de los animales silvestres y animales en zoológicos, la normatividad que aplicaría (y más en cuanto al tema de pandemia) es la Ley General de Vida Silvestre y su reglamento.

En este punto se debe destacar dos conceptos principalmente, el primero es Unidades de manejo para la conservación de vida silvestre y el segundo concepto Predios o instalaciones que manejan vida silvestre.

Las unidades de manejo para la conservación de vida silvestre son definidas como los predios e instalaciones registrados que operan de conformidad con un plan de manejo aprobado y dentro de los cuales se da seguimiento permanente al estado del hábitat y de poblaciones o ejemplares ${ }^{40}$. Mientras que se consideran como Predios o Instalaciones que Manejan Vida Silvestre a los criaderos intensivos, viveros, jardines botánicos o similares que manejen vida silvestre de manera confinada con propósitos de reproducción controlada de especies o poblaciones para su aprovechamiento con fines comerciales ${ }^{41}$.

Continuando el hilo de nuestro tema, la SEMARNAT es quien se coordinará con la SADER para el caso de las enfermedades y plagas que afecten a la fauna silvestre.

La SEMARNAT pide a las Unidades de Manejo para la Conservación de la Vida Silvestre (UMAS) y a los Predios o Instalaciones que Manejan Vida Silvestre (PIMVS), reforzar sus medidas de bioseguridad para proteger a la fauna silvestre del COVID $-19^{42}$. Es de resaltar que este exhorto que ha realizado la SEMARNAT ha sido sólo una solicitud con carácter de sugerencia y no de manera coercitiva. La Finalidad con la que ha hecho este exhorto dicha secretaría es la de evitar que los animales se contagien y sufran las consecuencias de la enfermedad derivado al contacto que se tiene con los cuidadores principalmente y las personas con síntomas relacionados al COVID-19.

Estos espacios ya cuentan en sus planes de manejo (autorizados por la SEMARNAT) con medidas para minimizar el riesgo de transmisión de enfermedades infecciosas entre especímenes y hacia los seres humanos $^{43}$. En cuanto se sospeche que algún animal silvestre pueda estar infectado por COVID-19 se le debe avisar a la SENASICA.

Así mismo, se señalan en diversos medios de comunicación que en los zoológicos ya han adoptado una estricta vigilancia epidemiológica y medidas adicionales como que las personas que pertenecen a grupos de riesgo y/o presenten cualquier tipo de síntoma respiratorio permanezcan en sus casas por cierto tiempo y no tengan contacto alguno con los ejemplares. Otras medidas adicionales fueron cerrar por un tiempo sus instalaciones ${ }^{44}$.

En México, según la asociación de Zoológicos, Criaderos y Acuarios de México (AZCARM), hay cerca de 110 instituciones miembros, y estas instituciones aseguran que a pesar del cierre de las instalaciones continúan las labores de mantenimiento en sus instalaciones, así como el monitoreo médico y alimenticio que requieren las especies, que en nuestro caso e interés es lo más importante (su bienestar) ${ }^{45}$.

Se sabe que han recibido donaciones y apoyo algunos de estos zoológicos principalmente alimentos, y esto es derivado a una ayuda de la SEMARNAT, a través de la Coordinación de la Dirección de Vida Silvestre ${ }^{46}$.

\footnotetext{
https:/espanol.cdc.gov/coronavirus/2019-ncov/community/veterinarians.html [Última consulta: 25 de noviembre de 2020]

${ }^{40}$ Artículo $3^{\circ}$. Fracción XLVIII de la Ley General de Vida Silvestre. Publicado en el Diario Oficial de la Federación el 3 de Julio de 2000. Última reforma publicada el 19 de enero de 2018. Página Web: http://www.diputados.gob.mx/LeyesBiblio/pdf/146_190118.pdf [Última consulta: 08 de septiembre de 2020]

${ }^{41}$ Artículo 2 fracción XV Bis del Reglamento de la Ley General de Vida Silvestre. Publicado en el Diario Oficial de la Federación el 30 de noviembre de 2006. Última reforma publicada el 9 de mayo de 2014.

http://www.diputados.gob.mx/LeyesBiblio/regley/Reg_LGVS.doc [Última consulta: 25 de noviembre de 2020]

${ }^{42}$ La Dirección General de Salud Animal (del Servicio Nacional de Sanidad, Inocuidad y Calidad Agroalimentaria de la Secretaría de Agricultura y Desarrollo Rural) emitió el oficio B00.02.07.-105 1444- 2020 fechado el 14 de abril del 2020 en el que se establecen las medidas básicas que deben llevarse a cabo por los médicos veterinarios dedicados a la atención de animales de zoológico, en el que se incluye a los caninos y felinos domésticos y silvestres. En este oficio se establecen las medidas ya establecidas en el presente protocolo, descritas a continuación, además de la manera de llevar a cabo la notificación correspondiente en caso de sospechar de COVID-19 en animales bajo cuidado humano en los zoológicos.

PROTOCOLO DE BIOSEGURIDAD APLICABLE DURANTE LA CONTINGENCIA DE COVID-19 PARA PRIMATES NO HUMANOS, FELINOS NO DOMÉSTICOS Y OTRAS ESPECIES SILVESTRES, EN LA DIRECCIÓN GENERAL DE ZOOLÓGICOS Y CONSERVACIÓN DE LA FAUNA SILVESTRE. Página

Web:https://www.sedema.cdmx.gob.mx/storage/app/media/DGZCFS/ProtocoloPrimatesFelinosCOVID19.pdf [Última consulta: 25 de noviembre de 2020]

${ }^{43}$ SEMARNAT. Semarnat pide a UMAS y PIMVS reforzar medidas de bioseguridad para proteger a la fauna silvestre del COVID19. Página Web: https://www.gob.mx/semarnat/prensa/semarnat-pide-a-umas-y-pymvs-reforzar-medidas-de-bioseguridad-paraproteger-a-la-fauna-silvestre-del-covid-19 [Última consulta: 08 de septiembre de 2020]

${ }^{44}$ PORTAL AMBIENTAL. Página Web:https://www.portalambiental.com.mx/biodiversidad/20200407/piden-reforzar-bioseguridadpara-proteger-a-fauna-silvestre-de-covid-19 [Última consulta: 25 de noviembre de 2020]

${ }^{45}$ Miranda, F. Durante aislamiento social, zoológicos han rescatado 600 animales. Periódico Milenio (México, 2020) Página Web: https://www.milenio.com/ciencia-y-salud/sociedad/aislamiento-social-zoologicos-rescatado-600-animales [Última consulta: 08 de septiembre de 2020]

${ }^{46}$ SEMARNAT. Comunicado de Prensa Núm. 53/20 Ciudad de México, a 22 de abril de 2020. Página web:
} 
De forma independiente a las medidas dictadas por cada una de las entidades federativas, en la Asociación antes mencionada, AZCARM, se constituyó un Comité de Reapertura para desarrollar los Lineamientos de Seguridad Sanitaria Zoológicos, Criaderos y Acuarios, un protocolo con "estrictas medidas de higiene y seguridad". ${ }^{47}$

Otro protocolo que se aplicó debido al abandono (por ignorancia, error, miedo a adquirir el virus) o bien porque ya no pueden seguir proporcionando un correcto bienestar a los Animales Silvestres de particulares las UMA han seguido recibiendo animales rescatados por la Procuraduría Federal de Protección al Ambiente. Sólo en los últimos meses, aseguran que les han dejado en custodia 600 especies $^{48}$.

Para cerrar este apartado nos podemos percatar en esta sección de los animales silvestres y animales en zoológicos que la SEMARNAT es quien se coordinará con la SADER para el caso de las enfermedades y plagas que afecten a la fauna silvestre y que ha habido un estricto seguimiento y fortalecimiento a las medidas de bioseguridad con la finalidad de proteger la vida y ejemplares de vida silvestre principalmente aquellos que se encuentran en manos de los zoológicos.

¿Qué ha sucedido en cuanto a los animales en la producción? En esta clasificación para el caso de las pandemias debemos tomar en cuenta la Ley Federal de Sanidad Animal. En ella debemos tener en mente las disposiciones en materia de buenas prácticas pecuaria, las cuales son actos administrativos de carácter general relacionados con la disminución de los peligros físicos, químicos y microbiológicos que pueden afectar la integridad de los bienes de origen animal para consumo animal o humano ${ }^{49}$.

Quien tiene competencia en esta sección es la SENASICA. El acto administrativo más importante es el Programa de Sanidad e Inocuidad Agroalimentaria, de éste se derivan las Campañas Zoosanitarias y estas se realizan a través de los Organismos Auxiliares de Sanidad Animal (OASA) ${ }^{50}$.

La SENASICA revisa y valida los programas de Campañas Zoosanitarias, además coordina la supervisión, seguimiento y evaluación para su correcta operación y el ejercicio de los recursos que operan los 31 OASA del país. $\operatorname{son}^{51}$ :

Las principales acciones dentro del Programa de Sanidad e Inocuidad Agroalimentaria que se realizan

- Componente Campañas Fito zoosanitarias

- Control o erradicación de plagas y enfermedades zoosanitarias reglamentadas

- Programas zoosanitarios en rumiantes

- Campaña Nacional contra la Tuberculosis Bovina

- Campaña Nacional contra la Brucelosis en los animales

- Campaña Nacional para el control de la Garrapata Boophilus spp

- Campaña Nacional contra la Rabia en Bovinos y especies ganaderas

- Programas zoosanitarios en aves

- Influenza aviar

- Programas en abejas

- Varroasis de las abejas

- Programa de eliminación de animales positivos, reactores, expuestos y sospechosos

Un ejemplo de lo anterior en cuanto a programas y campañas, y de cómo se controlaría una enfermedad exótica sería cuando se confirmaron casos positivos de Enfermedad Hemorrágica Viral de los Conejos

\footnotetext{
https://www.gob.mx/semarnat/prensa/anticipa-semarnat-acciones-junto-con-instituciones-zoologicas-para-proteger-animalessilvestres [Última consulta: 25 de noviembre de 2020]

${ }^{47}$ Prensa Animal. Página Web: https://prensaanimal.com/zoologicos-y-acuarios-listos-para-reanudar-actividades/ [Última consulta: 27 de noviembre de 2020]

48 Oficio publicado por AZCARM en la página oficial de Facebook con fecha de 20 de mayo del 2020. Página Web: https://www.facebook.com/AZCARMX/photos/pcb.10158318226724036/10158318223044036 [Última consulta: 25 de noviembre de 2020]

${ }^{49}$ Artículo 4.- de la Ley Federal de Sanidad Animal. Publicado en el Diario Oficial de la Federación el 25 de julio de 2007. Última reforma publicado el 16 de febrero de 2018. Página Web: http://www.diputados.gob.mx/LeyesBiblio/pdf/LFSA_160218.pdf [Última consulta: 08 de septiembre de 2020]

${ }^{50}$ Los OASA se constituyen conforme lo establecido en la Ley Federal de Sanidad Animal, su reglamento y el trámite SENASICA 01-050. Operan recursos federales y estatales con base en lo establecido en el Convenio de Coordinación para el Desarrollo Rural Sustentable, suscrito entre la SADER y las entidades federativas, así como el Anexo Técnico de Ejecución Específico para la Operación del Programa de Sanidad e Inocuidad Agroalimentaria correspondiente. SENASICA. Operación y supervisión. Página Web: https://www.gob.mx/senasica/acciones-y-programas/operacion-y-supervision-de-proyectos-de-las-campanas-zoosanitarias [Última consulta: 25 de noviembre de 2020]

${ }^{51}$ Ídem.

206 Derecho Animal. Forum of Animal Law Studies, vol. 11/4
} 
(EHVC), en un predio de traspatio de un municipio de Chihuahua.

Tras la confirmación, el SENASICA puso en marcha las medidas contra epidémicas. El predio, que contaba con una población de 30 conejos domésticos, de los cuales murieron 11 por la enfermedad, fue despoblado en su totalidad y el personal oficial inició un proceso de limpieza y desinfección en dichas instalaciones ${ }^{52}$.

Es menester señalar que es fundamental que el Médico Veterinario Responsable Autorizado en adelante MVRA, tenga conocimiento de cuáles son las enfermedades y las plagas que se consideran de notificación obligatoria, dependiendo de su capacidad de difusión y contagio. La notificación a tiempo contribuye a la correcta operación del Sistema Nacional de Vigilancia Epidemiológica, por ejemplo, en el caso de rabia paralítica bovina o garrapata se debe reportar dentro de las veinticuatro horas siguientes a su descubrimiento a los oficiales de salud animal estatales o federales.

En caso de sospechar de alguna enfermedad exótica, esta deberá ser reportada de inmediato a la Comisión México- Estados Unidos para la Prevención de la Fiebre Aftosa y otras Enfermedades Exóticas (CPA) vía telefónica. También se puede reportar vía la aplicación AVISE para dispositivos móviles.

Un MVRA ${ }^{53}$ oficial llevará a cabo una evaluación clínica del animal y determinará si se procede a la toma y envío de muestras bajo estrictas condiciones de seguridad y actuar conforme a la Norma Oficial Mexicana NOM-054-ZOO-199 ESTABLECIMIENTO DE CUARENTENAS PARA ANIMALES Y SUS PRODUCTOS.

Volviendo al tema de la aplicación AVISE, con la ayuda del software de localización del equipo, la aplicación generará el punto geográfico de donde se envió la notificación para que los médicos veterinarios de la Comisión México-Estados Unidos para la Prevención de la Fiebre Aftosa y otras Enfermedades Exóticas de los Animales (CPA) del SENASICA acudan a revisar a los animales.

En cuanto se reporta la enfermedad, el sistema genera un folio para el usuario, proporciona un número telefónico para que pueda comunicarse en caso de tener alguna duda y lo invita a estar atento a la llamada del personal técnico del SENASICA para dar seguimiento a su denuncia ${ }^{54}$.

Acompañando a lo anterior, dicho organismo de agricultura (SENASICA) a través de la Dirección General de Inocuidad Agroalimentaria, Acuícola y Pesquera ${ }^{55}$ ha publicado los manuales de buenas prácticas pecuarias. Los manuales son usados como una medida de control para prevenir problemas de salud y calidad de los alimentos, constituyen la base para establecer cualquier programa de aseguramiento de la inocuidad. También en dichos manuales se presentan los elementos que constituyen un sistema de reducción de riesgos de contaminación con la finalidad de que el productor y todo el personal que labore en la unidad de producción conozca estas actividades que deben realizarse para asegurar la inocuidad de los alimentos. Actualmente existen los siguientes ${ }^{56}$ :

- Manual de Buenas Prácticas de Manejo y Envasado de la Miel

- Manual de Buenas Prácticas de Producción de Huevo para Plato

- Manual de Buenas Prácticas de Producción de Leche Bovina

- Manual de Buenas Prácticas de Producción de Leche Caprina

- Manual de Buenas Prácticas de Producción de Pollo de Engorda

- Manual de Buenas Prácticas de Producción en Granjas porcícolas

- Manual de Buenas Prácticas Pecuarias en la Producción de Carne de Ganado Bovino en Confinamiento

- Manual de Buenas Prácticas Pecuarias Sistema de Explotación Extensivo y Semi-Extensivo de Ganado Bovino de Doble propósito

- Manual de Buenas Prácticas de Producción de Miel

\footnotetext{
52 SENASICA. Detecta Agricultura casos de Enfermedad Hemorrágica Viral de los Conejos en Chihuahua. Página Web: https:/www.gob.mx/senasica/prensa/detecta-agricultura-casos-de-enfermedad-hemorragica-viral-de-los-conejos-en-chihuahua240091?idiom=es [Última consulta: 08 de septiembre de 2020]

${ }^{53}$ Médicos Veterinarios Responsable Autorizado.

${ }^{54}$ Secretaría de Agricultura y Desarrollo Social. Lanza Agricultura aplicación AVISE para notificar enfermedades exóticas de los animales. Página Web: https://www.gob.mx/agricultura/prensa/lanza-agricultura-aplicacion-avise-para-notificar-enfermedadesexoticas-de-los-animales?idiom=es [Última consulta: 08 de septiembre de 2020]

${ }^{55}$ Dentro de SENASICA, la DGIAAP (Dirección General de Inocuidad Agroalimentaria Acuícola y Pesquera) se encarga de establecer las políticas y marco normativo en materia de inocuidad de los alimentos, enfoca su actividad a la aplicación de los sistemas de reducción de riesgos y peligros de contaminación en los procesos industriales de la cadena agroalimentaria. Ver referencia en Página Web: https://nu3.com.mx/es/reconocimientos-externos/ [Última consulta: 27 de noviembre de 2020]

${ }^{56}$ SENASICA. Manuales de Buenas Prácticas. Página Web: http://publico.senasica.gob.mx/?doc=21454 [Última consulta: 08 de septiembre de 2020]
} 
Dichos manuales exponen lo referente a la salud e higiene del personal en contacto directo con los animales. Es importante seguir cada uno de los pasos ya que la contaminación en la Unidad de Producción (UP en adelante) existe en todo momento, por ejemplo, en los bebederos, comederos, mezcladoras de alimento y almacén, pues son fuentes fácilmente contaminadas por roedores, materia fecal, fluidos y tejidos corporales.

Asimismo, el equipo de mezclado y el área de almacenaje de alimentos son presas de hongos por lo que su limpieza y sanitización se debe realizar por lo menos una vez a la semana. También se debe contar con un equipo que supervise las operaciones del establo y supervise los programas en la UP ${ }^{57}$.

Para finalizar esta sección del trabajo debemos recordar que los agentes infecciosos son oportunistas y que las infecciones ocurren en animales con una débil inmunidad, por lo que se debe proporcionar un balance nutricional y un adecuado suministro de alimento que ayude a promover la función inmune de los animales. Así como también evitar a toda costa que los animales sufran de estrés constante y permanente. Es decir, deben tener un bienestar físico y un bienestar mental los animales no humanos ${ }^{58}$.

En conclusión, a este apartado de los animales de producción, todo riesgo se minimiza mejorando los procedimientos de Buenas Prácticas de Manufactura (BPM) en la industria alimentaria. El origen del virus está ampliamente vinculado a la cadena alimentaria. Se ha discutido sobre la fuente primaria del COVID 19, pero casi no queda ninguna duda sobre su origen animal, es decir la pandemia que nos afecta es un nuevo caso de zoonosis, una infección producida a través de un "salto de un hospedador" animal hacia la especie humana ${ }^{59}$.

Pero lamentablemente considero que no existe un real control por la SENASICA pues en los mismos manuales establecen que estas disposiciones son voluntarias y no coercitivas. Sólo señalan que el cumplimiento en la aplicación de dichos lineamientos en los manuales por los productores, serán reconocidos por el SENASICA a través de un certificado o reconocimiento de Buenas Prácticas Pecuarias en su respectivo sector de producción. Si no se cumpliesen dichas normativas (salvo las que deban de cumplirse obligatoriamente por las NOMS y disposiciones legales vigentes y aplicables) no hay una sanción por no cumplir los manuales.

Cerrando este apartado considero que se deben tomar en cuenta los lineamientos que se establecieron internacionalmente como el de la Organización de las Naciones Unidas para la Alimentación y la Agricultura, FAO, Guidelines to mitigate the impact of the COVID-19 pandemic on livestock production and animal health ${ }^{60}$. Sugiero esto como complemento ya que los lineamientos establecidos por la FAO están más robustecidos y abarcan disposiciones más reales a aplicarse bajo la óptica del Covid19, cuando los manuales antes citados se señalan para un procedimiento normal sin la óptica del Covid19. Aunque esta guía de la FAO tampoco es obligatoria para esta industria en México.

En el caso de los animales acuáticos, la Ley General de Pesca y Acuacultura Sustentables nos puntea que las medidas sanitarias tienen por objeto prevenir, controlar, combatir y erradicar enfermedades y plagas de las especies acuáticas vivas. La autoridad en este caso también es la SENASICA pero esta ocasión es a través de la Comisión Nacional de Acuacultura y Pesca.

Cuando se detecte o se tenga evidencia científica sobre la presencia o entrada inminente de enfermedades emergentes o de notificación obligatoria, que pongan en situación de emergencia sanitaria a una o varias especies acuícolas en todo o en parte del territorio nacional, la Secretaría instrumentará el Dispositivo Nacional de Emergencia de Sanidad Acuícola, que implicará la publicación inmediata del Acuerdo en el que se establezca la instrumentación urgente y coordinada de las medidas sanitarias que deberán aplicarse.

La Secretaría podrá acordar y convenir la creación de uno o varios fondos de contingencia para afrontar inmediatamente las emergencias sanitarias ${ }^{61}$.

Además de esta Ley debemos consultar las Buenas prácticas pesqueras y acuícolas ${ }^{62}$ y las siguientes

\footnotetext{
${ }^{57}$ Esta información la he extraído del Anexo A 1 del Manual de Buenas Prácticas en Producción de Leche Caprina en su apartado de Bioseguridad. Analizando todos los manuales de buenas prácticas disponibles contienen la misma información general en el rubro de buenas prácticas pecuarias en el control de fauna nociva y bioseguridad, por lo tanto, lo he enunciado en el trabajo de forma genérica para no explayarnos en cada uno de los manuales pues no es tema del presente trabajo.

ORGANISMO NACIONAL DE CERTIFICACIÓN Y VERIFICACIÓN AGROALIMENTARIA, A.C. Página web: http://cva.org.mx/files/BPP/manualdebuenaspracticascaprina.pdf [Última consulta: 25 de noviembre de 2020]

${ }^{58}$ Ídem.

${ }^{59}$ Silva-Jaimes, M.I. 2020. El SARS-CoV-2 y otros virus emergentes y su relación con la inocuidad en la cadena alimentaria. Scientia Agropecuaria 11(2): 267-277.

${ }^{60}$ FAO. Guidelines to mitigate the impact of the COVID-19 pandemic on livestock production and animal health Página Web: http://www.fao.org/3/ca9177en/CA9177EN.pdf [Última consulta: 08 de septiembre de 2020]

${ }^{61}$ SENASICA. Sanidad acuícola y Pesquera. Página Web: https://www.gob.mx/senasica/acciones-y-programas/sanidad-acuicola-ypesquera [Última consulta: 08 de septiembre de 2020]

${ }^{62}$ SENASICA. Manuales de Buenas Prácticas pecuarias acuícolas y pesqueras. Página Web. 
Normas Oficiales Mexicanas en materia de Sanidad Acuícola: NOM-011-PESC-1993, la cual regula la aplicación de cuarentenas; y la NOM-030-PESC-2000, la cual establece los requisitos para determinar la presencia de enfermedades virales.

Finalmente, en cuanto a este rubro para los animales en la experimentación o investigación debemos consultar la NOM-062-ZOO-1999 Especificaciones Técnicas para la Producción, Cuidado y Uso De Los Animales De Laboratorio ${ }^{63}$.Así como también deberemos remitirnos a las NOM antes citadas en nuestro documento: NOM-033-SAG/ZOO-2014 MÉTODOS PARA DAR MUERTE A LOS ANIMALES DOMÉSTICOS Y SILVESTRES y la NOM-054-ZOO-1996 ESTABLECIMIENTO DE CUARENTENAS PARA ANIMALES Y SUS PRODUCTOS.

En el caso del rubro de los animales acuáticos y los animales en la experimentación o investigación, considero que no hay mucha información en los medios de comunicación, que nos puedan revelar el impacto o las acciones más concretas y recientes a seguir ante una pandemia.

\section{Conclusiones}

Cómo se podrá constatar este trabajo es una introducción, mismo que posteriormente podrá ser extendido, pues podemos constatar que si bien existe normatividad y protocolos diversos ante una pandemia, considero que estos se encuentran de forma dispersa. Hay que remitirse uno a uno a diversos documentos cuando en mi opinión se debería tener en un solo documento o manual oficial (con carácter vinculatorio y no sugerencias o circulares con toda la información de forma ordenada, más concreta del actuar ante una pandemia como la actual, la del COVID-19. Cabe destacar que mi objetivo no es el de que prescindamos de las distintas normas existentes que se acoplan a las características de cada especie. Si no precisamente dar paso a un documento oficial y nacional que incluya todos los casos y protocolos revisados con la finalidad de que no quepa duda o error alguno.

Si bien existen protocolos establecidos para el país de México, considero personalmente que aún que es un tanto desconocido este tema de sanidad animal para los habitantes del país, sobre todo si no estás en el medio. Una propuesta para que este tema pueda ser difundido de manera eficaz es realizar programas o campañas de concientización del presente tema llevándolo a todos los niveles educativos presentes en el país.

Otra conclusión al presente trabajo es revisar si la coordinación entre las autoridades citadas a lo largo del documento es realmente efectiva o no, puesto que por un lado existe una extensa normatividad relacionada al tema de pandemia, por otro lado, no sabemos con certeza si está bien aplicada.

Así mismo, podemos reflexionar que no se subraya aún la importancia del bienestar animal propiamente pues la normatividad solamente se enfoca en la salud humana (bajo una perspectiva antropocéntrica especista), y esto no debe ser así, deben estar al mismo nivel tanto la salud humana como la salud animal y como lo mencioné antes, nunca hay que eludir la salud de los animales.

Finalmente para cerrar este trabajo debo señalar que concuerdo con Christine Kreuder, investigadora del Instituto One Health que la clave de estos nuevos virus es la intrusión de los humanos en la naturaleza ${ }^{64}$ :

La propagación de virus desde animales es un efecto directo de nuestras acciones sobre la vida salvaje y sus hábitats. La consecuencia es que están compartiendo virus y eso amenaza la supervivencia de especies, a la vez que aumenta el riesgo de propagación.

Concuerdo con Kreuder en la medida de que considero firmemente que debemos de insistir y seguir velando por el bienestar animal de los animales desde el punto de vista de que no debemos seguir entrometiéndonos de manera innecesaria en sus vidas. Pues al hacerlo precisamente seguimos corriendo el riesgo de seguir adquiriendo nuevas enfermedades, algunas cada vez más mortales para el ser humano.

\section{Índice de Fuentes}

\section{Legislativas}

\footnotetext{
https://www.gob.mx/senasica/documentos/manuales-de-buenas-practicas-pecuarias-acuicolas-y-pesqueras

63 NOM-062-ZOO-1999 Especificaciones Técnicas para la Producción, Cuidado y Uso De Los Animales De Laboratorio. Publicado en el Diario Oficial de la Federación el 22 de agosto de 2001. Página Web:

https://www.gob.mx/cms/uploads/attachment/file/563492/NOM-062-ZOO-1999_220801.pdf [Última consulta: 08 de septiembre de $2020]$

${ }^{64}$ GONZALEZ, V. ¿Está relacionada la propagación de la COVID-19 con la pérdida de biodiversidad? Publicado en la Revista Muy Interesante (Madrid, 2020) Página Web: https://www.muyinteresante.es/naturaleza/articulo/esta-relacionada-la-propagacion-de-lacovid-19-con-la-perdida-de-biodiversidad-701586341971 [Última vez citadas el 9 de septiembre de 2020]
} 
- Constitución Política de los Estados Unidos Mexicanos. Publicado en el Diario Oficial de la Federación el 05 de febrero de 1917. Última reforma el día 08 de mayo de 2020. Página Web: http://www.diputados.gob.mx/LeyesBiblio/pdf/1_080520.pdf [Última consulta: 08 de septiembre de 2020]

- Ley Federal de Sanidad Animal. Publicada en el Diario Oficial de la Federación el 25 de julio de 2007. Última reforma el día 16 de febrero de 2018. Página Web: http://www.diputados.gob.mx/LeyesBiblio/pdf/LFSA_160218.pdf [Última consulta: 08 de septiembre de 2020]

- Ley General de Salud. Publicada en el Diario Oficial de la Federación el 7 de febrero de 1984. Última reforma publicada el 24 de enero de 2020. Página Web: http://www.diputados.gob.mx/LeyesBiblio/pdf/142_240120.pdf [Última consulta: 08 de septiembre de 2020]

- Ley General de Vida Silvestre. Publicado en el Diario Oficial de la Federación el 3 de Julio de 2000. Última reforma publicada el 19 de enero de 2018. Página Web: http://www.diputados.gob.mx/LeyesBiblio/pdf/146_190118.pdf [Última consulta: 08 de septiembre de 2020]

- Ley Orgánica de la Administración Pública Federal. Publicado en el Diario Oficial de la Federación el 29 de diciembre de 1976. Última reforma el día 22 de enero de 2020. Página Web: http://www.diputados.gob.mx/LeyesBiblio/pdf/153_220120.pdf [Última consulta: 08 de septiembre de 2020]

- Reglamento de la Ley Federal de Sanidad Animal. Publicada en el Diario Oficial de la Federación el 21 de mayo de 2012. Página Web: http://www.diputados.gob.mx/LeyesBiblio/regley/Reg_LFSA.pdf [Última consulta: 08 de septiembre de 2020]

- DECRETO por el que se ordenan diversas acciones en materia de salubridad general, para prevenir, controlar y combatir la existencia y transmisión del virus de influenza estacional epidémica. Publicada en el Diario Oficial de la Federación el 25 de abril de 2020. Página Web: http://dof.gob.mx/nota_detalle.php?codigo $=5088366 \&$ fecha $=25 \% 2 F 04 \% 2 F 2009$ [Última consulta: 24 de noviembre de 2020]

- NOM-033-SAG/ZOO-2014, Métodos para dar Muerte a los Animales Domésticos y Silvestres. Publicado en el Diario Oficial de la Federación el día 26 de agosto de 2015. Página web: https://normateca.agricultura.gob.mx/sites/default/files/normateca/Documentos/NORMA\%20Ofici al\%20Mexicana\%20NOM\%20033SAG\%20ZOO\%202014\%2C\%20M\%C3\%A9todos\%20para\%2 0dar\%20muerte $\% 20 \mathrm{a} \% 201 \mathrm{los} \% 20$ animales $\% 20 \mathrm{dom} \% \mathrm{C} 3 \% \mathrm{~A} 9$ sticos\%20y\%20silvestres.pdf [Última consulta: 08 de septiembre de 2020]

- NOM-046-ZOO-1995, SISTEMA NACIONAL DE VIGILANCIA EPIZOOTIOLÓGICA. Publicado en el Diario Oficial de la Federación el día 19 de febrero de 1997. Última reforma el 29 de enero de 2001. Página web: http://publico.senasica.gob.mx/includes/asp/download.asp?IdDocumento=530\&IdUrl=1014\&objet $\mathrm{o}=$ Documento\&IdObjetoBase $=530 \&$ down=true [Última consulta: 08 de septiembre de 2020]

- NOM-062-ZOO-1999 Especificaciones Técnicas para la Producción, Cuidado y Uso De Los Animales De Laboratorio. Publicado en el Diario Oficial de la Federación el 22 de agosto de 2001. Página Web: https:/www.gob.mx/cms/uploads/attachment/file/563492/NOM-062-ZOO1999_220801.pdf [Última consulta: 08 de septiembre de 2020]

- Norma Mexicana AA 165 SCFI 2014. Publicado en el Diario Oficial de la Federación el día 22 de septiembre de 2014. Página Web: http://www.economia-nmx.gob.mx/normas/nmx/2010/nmx-aa165-scfi-2014.pdf [Última consulta: 08 de septiembre de 2020]

- Acuerdo mediante el cual se dan a conocer en los Estados Unidos Mexicanos las enfermedades y plagas exóticas y endémicas de notificación obligatoria de los animales terrestres y acuáticos. Publicado en el Diario Oficial de la Federación el 29 de noviembre de 2018.Página Web: http://www.dof.gob.mx/nota_detalle.php?codigo $=5545304 \&$ fecha $=29 / 11 / 2018$ [Última consulta: 08 de septiembre de 2020]

\section{Jurisprudenciales}

\section{Nacionales}


- Tesis: 2a. CVIII/2014 (10a.) emitida por la Segunda Sala de la Suprema Corte de Justicia de la Nación en la Décima Época, publicada en la Gaceta del Semanario Judicial de la Federación, Libro 12, noviembre de 2014, Tomo I, Pág. 1192. SALUD. DERECHO AL NIVEL MÁS ALTO POSIBLE. ÉSTE PUEDE COMPRENDER OBLIGACIONES INMEDIATAS, COMO DE CUMPLIMIENTO PROGRESIVO.

\section{Otras fuentes}

\section{Literatura}

- ANAYA, G. Antropocentrismo ¿Un concepto equívoco? (México, 2014) 2. Disponible en la página web: https://entretextos.leon.uia.mx/num/17/articulo.php?id=2 pdf [Última consulta: 27 de noviembre de 2020]

- FAO. La Fauna Silvestre en un clima cambiante. Estudios Fao-Monte 167. (Roma, 2013) Página Web: http://www.fao.org/3/i2498s/i2498s.pdf [Última consulta: 26 de noviembre de 2020]

- FAO. Guidelines to mitigate the impact of the COVID-19 pandemic on livestock production and animal health. Página Web: http://www.fao.org/3/ca9177en/CA9177EN.pdf [Última consulta: 08 de septiembre de 2020]

- GONZALEZ, V. ¿Está relacionada la propagación de la COVID-19 con la pérdida de biodiversidad? Publicado en la Revista Muy Interesante (Madrid, 2020) Página Web: https://www.muyinteresante.es/naturaleza/articulo/esta-relacionada-la-propagacion-de-la-covid19-con-la-perdida-de-biodiversidad-701586341971 [Última vez citadas el 9 de septiembre de 2020]

- RODRÍGUEZ, M. La Constitución en esquemas. (Ciudad de México, 2015) Editorial Tirant lo Blanch. 233

- SANTILlANA, G. Virus SARS - Cov - 2. Enfermedad COVID - 19. La emergencia de salud pública ante la legislación mexicana. (Ciudad de México, 2020) Editorial Tirant lo Blanch. Diversas páginas.

- PROTOCOLO DE BIOSEGURIDAD APLICABLE DURANTE LA CONTINGENCIA DE COVID-19 PARA PRIMATES NO HUMANOS, FELINOS NO DOMÉSTICOS Y OTRAS ESPECIES SILVESTRES, EN LA DIRECCIÓN GENERAL DE ZOOLÓGICOS Y CONSERVACIÓN DE LA FAUNA SILVESTRE. Página Web: https://www.sedema.cdmx.gob.mx/storage/app/media/DGZCFS/ProtocoloPrimatesFelinosCOVID 19.pdf [Última consulta: 25 de noviembre de 2020]

- SILVA-JAIMES, M.I. 2020. El SARS-CoV-2 y otros virus emergentes y su relación con la inocuidad en la cadena alimentaria. Scientia Agropecuaria 11(2): 267-277.

- SUÁREZ, V ET AL. Epidemiology of COVID-19 in Mexico: from the 27th of February to the 30th of April 2020. Epidemiología de COVID-19 en México: del 27 de febrero al 30 de abril de 2020. Revista clínica española vol. 220,8 (2020). 463-471. DOI:10.1016/j.rce.2020.05.007

- VERDERA, J. Medwave 2008 Oct;8(9): e1716 doi: 10.5867/medwave.2008.09.1716 Página web: https://www.medwave.cl/link.cgi/Medwave/Revisiones/RevisionTemas/1716?ver=sindiseno

- VON AGUILAR, G. Derecho y pandemias. (Ciudad de México, 2019) Editorial Tirant lo Blanch México. Diversas páginas.

\section{Otros}

- AZCARM en la página oficial de Facebook con fecha de 20 de mayo del 2020. Página Web: https://www.facebook.com/AZCARMX/photos/pcb.10158318226724036/10158318223044036 [Última consulta: 25 de noviembre de 2020]

- CENAPRECE. Página Web: http://www.cenaprece.salud.gob.mx/programas/interior/emergencias/descargas/pdf/Plan_Nacional _Influenza.pdf [Última consulta: 26 de noviembre de 2020]

- CENTROS PARA EL CONTROL Y LA PREVENCION DE ENFERMEDADES https://espanol.cdc.gov/coronavirus/2019-ncov/community/veterinarians.html [Última consulta: 25 de noviembre de 2020]

- GRUPO NU-3. Dirección general de inocuidad agroalimentaria acuícola y pesquera. Página Web: https://nu3.com.mx/es/reconocimientos-externos/ [Última consulta: 27 de noviembre de 2020]

- INDUSTRIA FARMACÉUTICA VETERINARIA DE MÉXICO. Página Web: 
https://infarvet.org.mx/salud-animal-300320/ [Última consulta: 08 de septiembre de 2020]

- MAYO CLINIC. https://www.mayoclinic.org/es-es/diseases-conditions/coronavirus/expertanswers/can-pets-get-coronavirus/faq-20486391=[Última consulta: 24 de noviembre de 2020]

- MIRANDA, F. Durante aislamiento social, zoológicos han rescatado 600 animales. Periódico Milenio (México, 2020) Página Web: https://www.milenio.com/ciencia-ysalud/sociedad/aislamiento-social-zoologicos-rescatado-600-animales [Última consulta: 08 de septiembre de 2020]

- ORGANISMO NACIONAL DE CERTIFICACIÓN Y VERIFICACIÓN AGROALIMENTARIA, A.C. Página web: http://cva.org.mx/files/BPP/manualdebuenaspracticascaprina.pdf [Última consulta: 25 de noviembre de 2020]

- PORTAL AMBIENTAL. Página Web: https://www.portalambiental.com.mx/biodiversidad/20200407/piden-reforzar-bioseguridad-paraproteger-a-fauna-silvestre-de-covid-19 [Última consulta: 25 de noviembre de 2020]

- PRENSA ANIMAL. Página Web: https://prensaanimal.com/zoologicos-y-acuarios-listos-parareanudar-actividades/ [Última consulta: 27 de noviembre de 2020]

- PROTLCUEM. Página Web:

http://www.protlcuem.gob.mx/swb/work/models/siam/posicionamiento/articulos_posicionamiento/ Clasificaci\%C3\%B3n\%20de\%20los\%20diferentes\%20tipos\%20de\%20normas\%20oficiales\%20m exicanas.pdf [Última consulta: 25 de noviembre de 2020]

- RAMOS C., investigador en Ciencias Médicas del Centro de Investigación sobre Enfermedades Infecciosas (CISEI) del Instituto Nacional de Salud Pública (INSP). Página web: https://www.insp.mx/avisos/4732-enfermedades-zoonoticas-18.html [Última consulta: 25 de noviembre de 2020]

- SECRETARÍA DE AGRICULTURA Y DESARROLlO SOCIAL. Lanza Agricultura aplicación AVISE para notificar enfermedades exóticas de los animales. Página Web: https://www.gob.mx/agricultura/prensa/lanza-agricultura-aplicacion-avise-para-notificarenfermedades-exoticas-de-los-animales?idiom=es [Última consulta: 08 de septiembre de 2020]

- SEMARNAT. Comunicado de Prensa Núm. 53/20 Ciudad de México, a 22 de abril de 2020. Página web: https://www.gob.mx/semarnat/prensa/anticipa-semarnat-acciones-junto-con-institucioneszoologicas-para-proteger-animales-silvestres [Última consulta: 25 de noviembre de 2020]

- SEMARNAT. Semarnat pide a UMAS y PIMVS reforzar medidas de bioseguridad para proteger a la fauna silvestre del COVID-19. Página Web: https:/www.gob.mx/semarnat/prensa/semarnatpide-a-umas-y-pymvs-reforzar-medidas-de-bioseguridad-para-proteger-a-la-fauna-silvestre-delcovid-19 [Última consulta: 08 de septiembre de 2020]

- SENASICA. Manuales de Buenas Prácticas pecuarias. https://www.gob.mx/senasica/documentos/manuales-cpa?state=published [Última vez citadas el 9 de septiembre de 2020]

- SENASICA. Sanidad acuícola y Pesquera. Página Web: https://www.gob.mx/senasica/acciones-yprogramas/sanidad-acuicola-y-pesquera [Última consulta: 08 de septiembre de 2020]

- SENASICA. Manuales de Buenas Prácticas pecuarias acuícolas y pesqueras. Página Web. https://www.gob.mx/senasica/documentos/manuales-de-buenas-practicas-pecuarias-acuicolas-ypesqueras

- SENASICA. Operación y supervisión. Página Web: https://www.gob.mx/senasica/acciones-yprogramas/operacion-y-supervision-de-proyectos-de-las-campanas-zoosanitarias [Última consulta: 08 de septiembre de 2020]

- SENASICA. Detecta Agricultura casos de Enfermedad Hemorrágica Viral de los Conejos en Chihuahua. Página Web: https://www.gob.mx/senasica/prensa/detecta-agricultura-casos-deenfermedad-hemorragica-viral-de-los-conejos-en-chihuahua-240091?idiom=es [Última consulta: 08 de septiembre de 2020]

- SENASICA. Manuales de Buenas Prácticas. Página Web: http://publico.senasica.gob.mx/?doc=21454 [Última consulta: 08 de septiembre de 2020]

- SENASICA. Recomendaciones para prevenir COVID-19 en animales. Página Web: https://www.gob.mx/senasica/articulos/recomendaciones-para-prevenir-covid-19-enanimales?idiom=es [Última consulta: 08 de septiembre de 2020]

- SENASICA. Emite Agricultura recomendaciones para prevenir y detectar contagio de la COVID19 en animales. Página Web: https://www.gob.mx/senasica/prensa/emite-agriculturarecomendaciones-para-prevenir-y-detectar-contagio-de-la-covid-19-en-animales-240184 [Última 
consulta: 08 de septiembre de 2020]

- SENASICA. Salud Animal. Acciones para mejorar el estatus zoosanitario del país. Página Web: https://www.gob.mx/senasica/acciones-y-programas/acciones-estrategicas-de-salud-animal.pdf [Última consulta: 08 de septiembre de 2020]

- SENASICA. Dispositivo Nacional de Emergencia de Sanidad Animal (DINESA). Establece medidas de prevención, control y erradicación. Página web: https:/www.gob.mx/senasica/accionesy-programas/dispositivo-nacional-de-emergencia-de-sanidad-animal-dinesa [Última consulta: 08 de septiembre de 2020]

- USDA. National Institute of Food and Agriculture. Importance of animal health. Página Web: https://nifa.usda.gov/topic/animal-health [Última consulta: 26 de noviembre de 2020] 